\title{
MAURICIO MENJÍVAR OCHOA Y RALPH SPRENKELS (EDS.). LA REVOLUCIÓN REVISITADA. NUEVAS PERSPECTIVAS SOBRE LA INSURRECCIÓN Y LA GUERRA EN EL SALVADOR. SAN SALVADOR: UCA EDITORES, 2018, 356 PP. ISBN 978- 99961-1-044-3
}

Mauricio Menjívar Ochoa Universidad de Costa Rica mauricio.menjivar@ucr.ac.cr

Ralph Sprenkels Universidad de Utrecht r_sprenkels@yahoo.es

Recepción: 4 de diciembre de 2017

Aceptación: 11 de diciembre de 2017 



\title{
MAURICIO MENJÍVAR OCHOA Y RALPH SPRENKELS (EDS.). LA REVOLUCIÓN REVISITADA. NUEVAS PERSPECTIVAS SOBRE LA INSURRECCIÓN Y LA GUERRA EN EL SALVADOR. SAN SALVADOR: UCA EDITORES, 2018, 356 PP. ISBN 978-99961-1-044-3.
}

Mauricio Menjívar Ochoa

Universidad de Costa Rica mauricio.menjivar@ucr.ac.cr

\author{
Ralph Sprenkels \\ Universidad de Utrecht \\ r_sprenkels@yahoo.es
}

En los últimos años, el estudio académico del conflicto armado salvadoreño ha tenido un notable crecimiento. La época en que cada cual, desde su trinchera, pensaba conocer la realidad del país y la verdad última sobre el conflicto, si bien no ha pasado del todo, ha abierto paso a una mayor certeza, sobre todo entre nuevas generaciones de historiadores y cientistas sociales, de que aún falta mucho por conocer. Este nuevo libro, que editamos bajo el título La revolución revisitada, que se inspira en esta nueva ola de fructífera inquietud intelectual, recopila trabajos inéditos de algunos de las y los principales impulsores del estudio contemporáneo de la guerra salvadoreña (1980-1992).

La revolución revisitada reúne once textos que interrogan facetas, sucesos, actores, y secuelas de este conflicto armado. El libro reúne los aportes de un grupo heterogéneo por su filiación académica, institucional y geográfica, con representación de El Salvador, Costa Rica, México, Países-Bajos, Argentina, Alemania y España. Ofrece una mirada sobre aspectos acuciantes tales como el entorno internacional del conflicto, el desarrollo de las organizaciones guerrilleras y sus disputas internas, los patrones de la violencia, 
la construcción discursiva del enemigo, la representación literaria del sujeto revolucionario y la transición democrática. Manteniendo distancia de las versiones maniqueas sobre la guerra salvadoreña, que a nuestro criterio han contribuido poco al estudio científico del conflicto, las distintas contribuciones evidencian lo fructífero de una nueva generación de estudios retrospectivos sobre la guerra salvadoreña, contribuciones que no solo documentan y analizan sino que, también, plantean cuestiones importantes que aún deben de profundizarse. De tal suerte, esta serie de trabajos constituye una muestra de la diversidad empírica, la profundidad reflexiva y la heterodoxia teórica de la reciente producción académica sobre la guerra en El Salvador.

En el primer capítulo, titulado "Revisitar la historia de la guerra civil salvadoreña: la necesidad de cada tiempo presente", Mauricio Menjívar Ochoa realiza un recuento de los temas abordados en el presente volumen, procurando inscribirlos en una discusión más amplia sobre la literatura académica producida desde los años ochenta. En este sentido, siguiendo a varios estudiosos de El Salvador, el autor realiza un recuento de la evolución de los diferentes énfasis y preocupaciones de dicha literatura, mostrando las diferentes capas temáticas marcadas por el espíritu de cada época. La década de los ochenta, por ejemplo, estuvo dominada por la literatura producida por autores simpatizantes con el movimiento revolucionario o con la lucha del pueblo salvadoreño. La década de los noventa, marcada por el uso de la categoría de "ideología", por el análisis de la voluntad política insurgente y por las características del régimen militar. La década del dos mil, más limitada, pero con la multiplicación de nuevos intereses de investigación, entre ellos, la cuestión de género, la relación entre represión y movilización, entre cambios económicos y evolución de la derecha salvadoreña, y la literatura de tipo testimonial. A partir de este recorrido, el trabajo discute sobre el aporte de La revolución revisitada, según las nuevas sensibilidades de nuestros tiempos.

En el capítulo 2, Alberto Martín Álvarez y Eudald Cortina realizan un necesario aporte a la comprensión de la historia de las organizaciones revolucionarias, sobre algunas de las cuales existen aún importantes vacíos. En este volumen, ellos se centran en la reconstrucción de la historia del Partido Comunista de El Salvador (PCS). Martín y Cortina profundizan en el 
conocimiento de la estrategia y la dinámica interna del Partido Comunista Salvadoreño en el período comprendido entre 1959 y 1970. Como señalan los autores "el análisis de este periodo, marcado por dos coyunturas clave -la Revolución Cubana y el abandono del partido por parte de su secretario general y un selecto grupo de militantes para formar las FPL-, es fundamental para la comprensión de la trayectoria del movimiento revolucionario salvadoreño en las décadas de los setenta y ochenta del pasado siglo” (p.21).

Otro aporte a esta historia de las organizaciones guerrilleras se presenta en el capítulo 3. En éste, Jorge Juárez analiza la dinámica de incorporación a la guerrilla de las Fuerzas Populares de Liberación (FPL) vista desde el campesinado. Su investigación permite entrever que las razones de la incorporación al movimiento armado revolucionario trascendieron a los influjos de la teología de la liberación y de las mismas facciones de la guerrilla. Juárez sugiere que entre los campesinos que se incorporaron a la guerrilla existieron motivaciones muy distintas a las del compromiso ideológico: el amor, el estatus legal en el país y la inexistencia de opciones debido al incremento de la violencia, crearon condiciones que llevaron a mucha gente a participar en la guerra. Sin duda, ello abre nuevas perspectivas para entender el apoyo de la guerrilla entre el campesinado.

El trabajo de Ralph Sprenkels y Michelle Melara -capítulo 4- revisa las tendencias de un componente básico de la guerra: la persecución violenta. Sistematiza las fuentes disponibles y analiza las dinámicas de la persecución violenta para el período entre 1970 a 1991, reflexionando sobre los patrones y las variaciones que presentan estas modalidades de violencia en el tiempo. El texto evidencia las importantes diferencias territoriales y temporales que se dieron en torno a la violencia política en el país para el período 1970 a 1991 y explora las lógicas subyacentes a estas variaciones. Propone, asimismo, la construcción de una agenda de investigación en torno a distintos aspectos de la violencia asociada con el conflicto armado en El Salvador.

Los siguientes tres trabajos, ubicados desde diferentes enfoques, tienen como objeto de su análisis a los discursos y la historia intelectual en relación al conflicto armado. En el capítulo 5, Patricia Alvarenga Venutuolo interroga la forma en que se representa al sujeto revolucionario en el discur- 
so literario, mientras que Michelle Melara, en el capítulo 6, analiza la forma en que se construye al enemigo en el discurso de Roberto d'Abuisson. Igualmente interesado en la lucha discursiva, el trabajo de Mauricio Menjívar Ochoa-capítulo 7- analiza las disputas dentro de la guerrilla salvadoreña en torno a la salida negociada al conflicto. El trabajo de Alvarenga, que se inscribe en el debate sobre las diferencias entre literatura e historia, propone un diálogo entre las discursividades de la ficción literaria y de las ciencias sociales, teniendo como un eje fundamental de análisis la memoria. Melara, por su parte, trabaja el mensaje de D'Abuisson en el período que va de 1980 a 1991, a partir de los referentes teóricos del análisis del discurso. Menjívar Ochoa, por último, recurre a la historia conceptual y a la historia intelectual para intentar inscribir al discurso en su contexto e intencionalidad política durante el período comprendido entre 1980 y 1984. En él, propone que las Fuerzas Populares de Liberación "Farabundo Martí" (FPL), comenzaba a posicionar discursivamente la posibilidad de negociar con ciertos sectores de la burguesía. Esto tendía a aproximar a las FPL a las demás organizaciones guerrilleras, cada vez más orientadas a utilizar la guerra para presionar un salida negociada al conflicto. En este contexto fue asesinada la número dos de las FPL, la Comandante "Ana María”, a lo que siguió el suicidio del número uno de dicha organización, el Comandante "Marcial". El texto que le sirve de base para el trabajo que presenta Menjívar Ochoa se presenta en el capítulo 8. Se trata del documento "Sobre oligarquía, burguesía y sus sectores y fracciones y los espacios de alianzas o convergencias", producido al interior de las Fuerzas Populares de Liberación (FPL), probablemente por Rafael Menjívar Larín. Ex rector de la Universidad Nacional de El Salvador, Menjívar Larín fue militante e intelectual orgánico de aquel partido.

Los siguientes dos trabajos optan por una mirada que privilegia la dinámica internacional alrededor del conflicto armado salvadoreño. El de Dirk Kruijt -capítulo 9- que analiza las relaciones entre Cuba y los movimientos revolucionarios de Centroamérica, particularmente los de Guatemala, Nicaragua y El Salvador. Se trata, según Kruijt, de una dinámica de solidaridad y de apoyo. El segundo es el capítulo de Carmen ElenaVillacorta -número 10-, que avanza en el análisis del papel jugado por diferentes países 
de América Latina en torno a tres iniciativas: la declaración franco-mexicana, la conformación del grupo de Contadora y el trabajo realizado por el grupo de Esquipulas.

El trabajo de Heidrun Zinecker, con el que finaliza el libro -capítulo 11-, discute la hipótesis que apunta a la existencia de una transición a la democracia cuyo inicio ubica en el golpe militar de octubre de 1979 y que dura aún después de terminada la guerra. También analiza la hipótesis de que hubiese sido posible evitar la guerra, revisitando así una de las preocupaciones recurrentes de las y los estudiosos sobre este período de la historia salvadoreña.

Como conjunto, La revolución revisitada se caracteriza por un estudio riguroso de distintos aspectos del conflicto, empleando métodos científicos y evitando versiones ideologizadas. Ciertamente, no pretendemos cerrar el debate académico sobre el conflicto armado en El Salvador. ¡Al contrario! Esperamos más bien, con este libro, haber contribuido a abrir un poco más el debate. Para que la guerra salvadoreña no sea reducida a propaganda o a olvido necesita de una atención académica mucho mayor de lo que ha tenido hasta ahora. Solo así podremos también extraer de esta experiencia histórica los aprendizajes necesarios para evitar el reciclaje de la intolerancia y la violencia. 